\title{
Almanaque digital: a "escrevivência"1 da mulher negra e as vozes silenciadas na literatura brasileira
}

\author{
Digital almanac: "escrevivência" of the black woman and the silenced voices in \\ Brazilian literature
}

\author{
(iD) Denise Stefanoni Combinato \\ Doutorado em Saúde Coletiva \\ Departamento de Humanidades - ITA. \\ São José dos Campos, SP - Brasil. \\ denisecombinato@hotmail.com \\ Deborah Caroline Ramos Bahiense \\ Graduanda em Pedagogia \\ Universidade Virtual do Estado de São Paulo - UNIVESP. \\ São José dos Campos, SP - Brasil. \\ deborahcsramos@gmail.com \\ D \\ Gislaine Aparecida dos Reis \\ Pós-Graduação em Administração de Empresas \\ Fundação Armando Álvares Penteado - FAAP. \\ São José dos Campos, SP - Brasil. \\ deborahcsramos@gmail.com
}

Resumo: O objetivo deste trabalho foi recuperar a história de vida e a produção de escritoras negras - Antonieta de Barros, Carolina Maria de Jesus, Conceição Evaristo, Maria Firmina dos Reis e Ruth Guimarães, a fim de promover uma reflexão sobre gênero e racismo com alunos de Ensino Médio. Foi elaborado um almanaque digital interativo a partir do estudo do papel da mulher negra na literatura e na sociedade. O almanaque contou com elementos clicáveis, QR Codes e/ou links para atividades em plataformas externas, como jogos, testes e vídeos. Através de uma aula on-line para apresentação do almanaque a alunos de uma Escola Estadual Integral do interior do estado de São Paulo, foi possível identificar reflexões sobre gênero e raça, inclusiv e com testemunho de vida dos alunos. A maioria não conhecia essas escritoras e, segundo avaliação posterior das professoras da turma, o almanaque digital despertou o interesse dos alunos pela literatura.

Palavras chave: almanaque digital; literatura afro-brasileira; autoras negras; racismo; gênero.

Abstract: The purpose of this work was to recover the life story and production of black female writers - Antonieta de Barros, Carolina Maria de Jesus, Conceição Evaristo, Maria Firmina dos Reis, and Ruth Guimarães, to promote reflection on gender and racism with high school students. We designed an interactive digital almanac from the study of the role of the black woman in literature and society. The almanac had clickable elements, QR Codes, and links to activities on external platforms, such as games, tests, and videos. Through an online class carried out to present the almanac to students of a full-time state school inland from São Paulo, we could identify reflections on gender and race, including students' life stories. Most of the students hadn't known the writers and, according to subsequent evaluation from the class teachers, the digital almanac has awoken students' interest in literature.

Key-words: digital almanac; Afro-Brazilian literature; black female writers; racism; gender.

Cite como

(ABNT NBR 6023:2018)

COMBINATO, Denise Stefanoni; BAHIENSE, Deborah Caroline Ramos, REIS, Gislaine Aparecida. Almanaque digital: a "escrevivência"2 da mulher negra e as vozes silenciadas na literatura brasileira. Dialogia, São Paulo, n. 39, p. 1-19, e20429, set./dez. 2021. Disponível em: https://doi.org/10.5585/39.2021.20429.

American Psychological Association (APA)

Combinato, D. S., Bahiense, D. C. R., \& Reis, G. A. (2021, set./dez.) A comunidade Mumbuca e as plantas medicinais: tecendo aproximações entre saberes tradicionais e ensino de química. Dialogia, São Paulo, 39, p. 1-19, e20429. https://doi.org/10.5585/39.2021.20429.

${ }^{1}$ A Portuguese neologism from the words 'escrever' (to write) e 'vivência' (one's life experience).

${ }^{2}$ A Portuguese neologism from the words 'escrever' (to write) e 'vivência' (one's life experience). 


\title{
Marcas de uma sociedade escravagista e patriarcal
}

\author{
"A nossa escrevivência não é para adormecer os da casa-grande e sim acordá-los de seus \\ sonos injustos" \\ Conceição Evaristo (EVARISTO, 2020, p.30).
}

Ainda que a escravidão tenha acontecido entre os séculos XVI e XIX no Brasil, até hoje negros e indígenas brasileiros experimentam o fardo da colonização e da escravidão "encerrada" há mais de 100 anos (NASCIMENTO; BENATTI, 2020).

O negro ainda é visto como inferior, suas competências ainda são questionadas e ele ainda é desprovido de oportunidades no meio social, educacional e profissional, sendo localizado na parte inferior da estrutura social.

A mulher negra, por sua vez, é a que mais sofre com a inferiorização e a discriminação, experienciando pobreza, exclusão e violência (NASCIMENTO; BENAT'TI, 2020).

\begin{abstract}
[...] Nós, mulheres negras, vivenciamos em nosso cotidiano múltiplas formas de violência: física, psicológica, sexual e simbólica; maior vitimização no tráfico de mulheres e drogas. Estamos mais expostas à violência produzida por atores armados da polícia (agentes do Estado Brasileiro!) e da marginalidade. Não será por outras razões que vivenciamos emoções e sentimentos de baixa autoestima, rejeição, medo, raiva, desilusão, tristeza, impotência, dor, insegurança, frustração e perda de identidade. (WERNECK; IRACI; CRUZ, 2012, p.14).
\end{abstract}

De acordo com o Atlas da Violência (IPEA, 2020), 4.519 mulheres foram assassinadas em 2018 no Brasil, ou seja, uma mulher foi assassinada a cada duas horas, sendo 68\% das vítimas negras. E, conforme levantamento realizado pelo Monitor da Violência, uma iniciativa do portal G1 em parceria com o Núcleo de Estudos da Violência da USP e o Fórum Brasileiro de Segurança Pública, os primeiros meses de 2020 registraram aumento nos índices de violência doméstica no Brasil, sendo as principais vítimas de feminicídio as mulheres negras, com $73 \%$ dos casos (REDE BRASIL ATUAL, 2020).

Os casos de homicídio com pessoas negras aumentaram 11,5\% na última década, de acordo com o Atlas da Violência (IPEA, 2020). E a taxa de violência com não negros fez o caminho inverso, com queda de $12,9 \%$.

Uma das explicações para esse cenário é o racismo estrutural.

Racismo é uma decorrência da própria estrutura social, ou seja, do modo "normal" com que se constituem as relações políticas, econômicas, jurídicas e até familiares, não sendo uma patologia social, nem um desarranjo institucional. O racismo é estrutural. Comportamentos individuais e processos institucionais são derivados de uma sociedade cujo racismo é regra e não exceção. O racismo é parte de um processo social que ocorre “pelas costas dos indivíduos e lhes parece legado pela tradição". (ALMEIDA, 2018, p.26). 
Em outras palavras, racismo estrutural é a prática de comportamentos preconceituosos e segregadores - ainda que involuntários - que estão enraizados na forma como foi construída nossa sociedade e que indiretamente ainda privilegia algumas raças em detrimento de outras, através de uma sociedade desenvolvida e consolidada com a base da discriminação.

Se não bastasse isso, a formação da sociedade brasileira é caracterizada por um modelo de família patriarcal, herança da cultura portuguesa que sofreu influência do passado medieval europeu e da sociedade muçulmana.

Desde o Brasil Colônia até os anos 1960, os papéis sexuais eram bem definidos, salvo raras exceções: ao marido pertencia o poder de decisão indiscutível, a tarefa de proteger e prover o sustento da esposa e dos filhos. À mulher cabia a organização da casa e os cuidados com a família. Os costumes e as tradições privadas e familiares eram apoiados e oficializados pelas leis e regras jurídicas. As relações familiares submetidas à influência do modelo patriarcal perduram até hoje, sendo a sua dominância mais marcante até o século XIX (SAMARA, 2002).

Em uma sociedade patriarcal, marcada pelo racismo estrutural, qual é a expressão da mulher negra na literatura?

Seja em textos literários ou não literários, em geral, a mulher negra é tida como objeto de aproveitamento e satisfação do homem, sendo seu corpo visto como instrumento de prazer do homem branco (SOUZA, 2008).

Pode-se observar a visão corrompida da mulher negra desde a formação da literatura brasileira. Não se dirige à mulher negra como mãe de família, cujo título era concedido apenas às mulheres brancas (EVARISTO, 2005).

Carneiro (2003) afirma que "as mulheres negras fazem parte de um contingente de mulheres [...] que são retratadas como antimusas da sociedade brasileira, porque o modelo estético de mulher é a mulher branca” (p.50).

Segundo Evaristo (2009),

\footnotetext{
A ficção ainda se ancora nas imagens do passado escravo, em que a mulher negra era considerada só como um corpo que cumpria as funções de força de trabalho, de um corpo-procriação de novos corpos para serem escravizados e/ou de um corpo-objeto de prazer do macho senhor.

Percebe-se que a personagem feminina negra não aparece como musa, heroína, romântica ou mãe. Mata-se no discurso literário a prole da mulher negra, não the conferindo nenhum papel no qual ela se afirme como centro de uma descendência. À personagem negra feminina é negada a imagem de mulher-mãe, perfil que aparece tantas vezes desenhado para as mulheres brancas em geral. (p.23).
}

A expressão da autora negra não é muito diferente da personagem negra. Estudos recentes descobriram produções femininas, algumas publicadas sob pseudônimo, em revistas, jornais e 
livros que se perderam com o passar dos anos. Por muito tempo, a escrita de mulheres negras foi ignorada pela crítica e assimilada como sem valor para a literatura (SOUZA, 2017).

Como a literatura dialoga com a realidade, percebe-se que ainda não há no Brasil um lugar onde não haja sofrimento para a mulher negra (NASCIMENTO, 2020). As escritoras negras, muitas vezes, escrevem suas vivências ou, nas palavras de Conceição Evaristo, suas “escrevivências", para delatar a humilhação e os silenciamentos sofridos, na expectativa de combater o racismo e reivindicar justiça.

Conforme Duarte (2014), algumas características da literatura afro-brasileira são:

[...] uma voz autoral afrodescendente, explícita ou não no discurso; temas afro-brasileiros; construções linguísticas marcadas por uma afro-brasilidade de tom, ritmo, sintaxe ou sentido; um projeto de transitividade discursiva, explícito ou não, com vistas ao universo recepcional; mas sobretudo, um ponto de vista ou lugar de enunciação política e culturalmente identificado à afrodescendência, como fim e começo. (p.29, grifo do autor).

A existência dessa literatura depende da inter-relação entre esses elementos: tema, autoria, ponto de vista, linguagem e direcionamento recepcional (DUARTE, 2014). Apesar dessa junção de características, é importante ressaltar que, assim como destacou o próprio autor no texto, existe um ponto de vista, um lugar de enunciação.

A partir da década de 2000, durante o governo Luís Inácio Lula da Silva, foi promulgada a Lei n. 10.639 (BRASIL, 2003) e, posteriormente, a Lei n. 11.645 (BRASIL, 2008), em que se estabeleceu, respectivamente, a obrigatoriedade na Rede de Ensino do estudo da História e Cultura Afro-Brasileira e a obrigatoriedade do estudo da História e Cultura Afro-Brasileira e Indígena. De acordo com essa legislação, tais conteúdos devem ser "ministrados no âmbito de todo o currículo escolar, em especial, nas áreas de educação artística e de literatura e história brasileiras." (BRASIL, 2008 , art. $1^{\circ}, \S 2^{\circ}$, grifo nosso).

Apesar dessa institucionalização, a literatura afro-brasileira, mais especificamente a produção literária de escritoras negras (nosso foco do estudo), ainda está longe de ter um prestígio acadêmico e social.

Nesse sentido, buscando dar visibilidade a essas vidas e obras, assim como promover uma reflexão junto à comunidade escolar sobre gênero e raça, foi elaborado um almanaque digital interativo, com conteúdo sobre a vida e a obra de cinco escritoras negras.

Esse projeto foi desenvolvido através de uma parceria entre alunas de graduação do curso de Letras e Pedagogia, vinculadas a uma Universidade Estadual Paulista, e uma Escola Estadual de Ensino Médio Integral do interior do estado de São Paulo - Brasil. O uso de ferramentas tecnológicas de aprendizagem era uma exigência do projeto curricular no qual as graduandas 
estavam matriculadas e a temática de machismo e racismo foi uma demanda apresentada pela escola.

\section{Um fazer crítico e tecnológico}

O trabalho do educador no contexto escolar deve ser direcionado por um fim, pela pertinência histórica da constituição humana e pela formação da consciência crítica dos estudantes. A consciência dos fins da educação escolar determina os meios pelos quais a ação pedagógica é realizada (BERNARDES, 2009).

Entendemos que, independente da estratégia, é preciso despertar os motivos desse aprender nos alunos - o que não se trata de deixar o aluno traçar seu processo de aprendizagem ou aprender sozinho, conforme preconizam as teorias do "aprender a aprender" para que os sujeitos se adaptem e acompanhem rapidamente as mudanças exigidas pela sociedade capitalista (DUARTE, 2001).

No que se refere à utilização das tecnologias digitais para o processo ensino-aprendizagem, uma vez superada a problemática de acesso e letramento digital de todos os sujeitos envolvidos no processo educacional, essa tecnologia pode favorecer vários meios de ensino-aprendizagem, assim como de avaliação da aprendizagem.

Mesmo com a diversidade de perfis dos alunos e das preferências de cada um em relação às estratégias de ensino-aprendizagem, dificilmente as tecnologias digitais não serão bem acolhidas pelos estudantes, já que elas estão cada vez mais presentes no cotidiano das pessoas, especialmente dos mais jovens. Conforme afirmam Machado e Lima (2017, p.45), “os alunos são nativos digitais, pois têm uma convivência íntima com a tecnologia”.

Ainda assim, precisam se apropriar desse aparato tecnológico de maneira crítica e reflexiva para que o utilizem adequadamente na vida escolar e social, o que depende necessariamente da formação docente e das condições adequadas de trabalho para o planejamento e o desenvolvimento de suas atividades pedagógicas (ALVES; SANTOS; FREITAS, 2017).

\footnotetext{
A integração das TDICs [tecnologias digitais de informação e comunicação] nos processos de ensino com foco na aprendizagem e no desenvolvimento integral do sujeito requer, por parte dos professores, tempo para desenvolver a fluência tecnológica, o planejamento e o desenvolvimento com autoria de materiais pedagógicos. (ALVES; SANTOS; FREITAS, 2017, p.326).
}

Buscando romper a fronteira entre pesquisador-pesquisado, sujeito-objeto, promovendo um maior envolvimento entre os sujeitos envolvidos, esse projeto orientou-se pelos princípios da pesquisa-ação, fundamentado na Psicologia histórico-cultural e Pedagogia histórico-crítica. 
Através da articulação entre literatura afro-brasileira e ferramentas tecnológicas de aprendizagem, desenvolvemos um almanaque digital interativo, com elementos clicáveis, QR Codes e/ou links para atividades em plataformas externas, como jogos, testes e vídeos. Ele foi dividido nas seguintes seções: biografia das autoras, trechos literários, curiosidades, caça-palavras, cruzadinhas, quiz e indicações de materiais complementares.

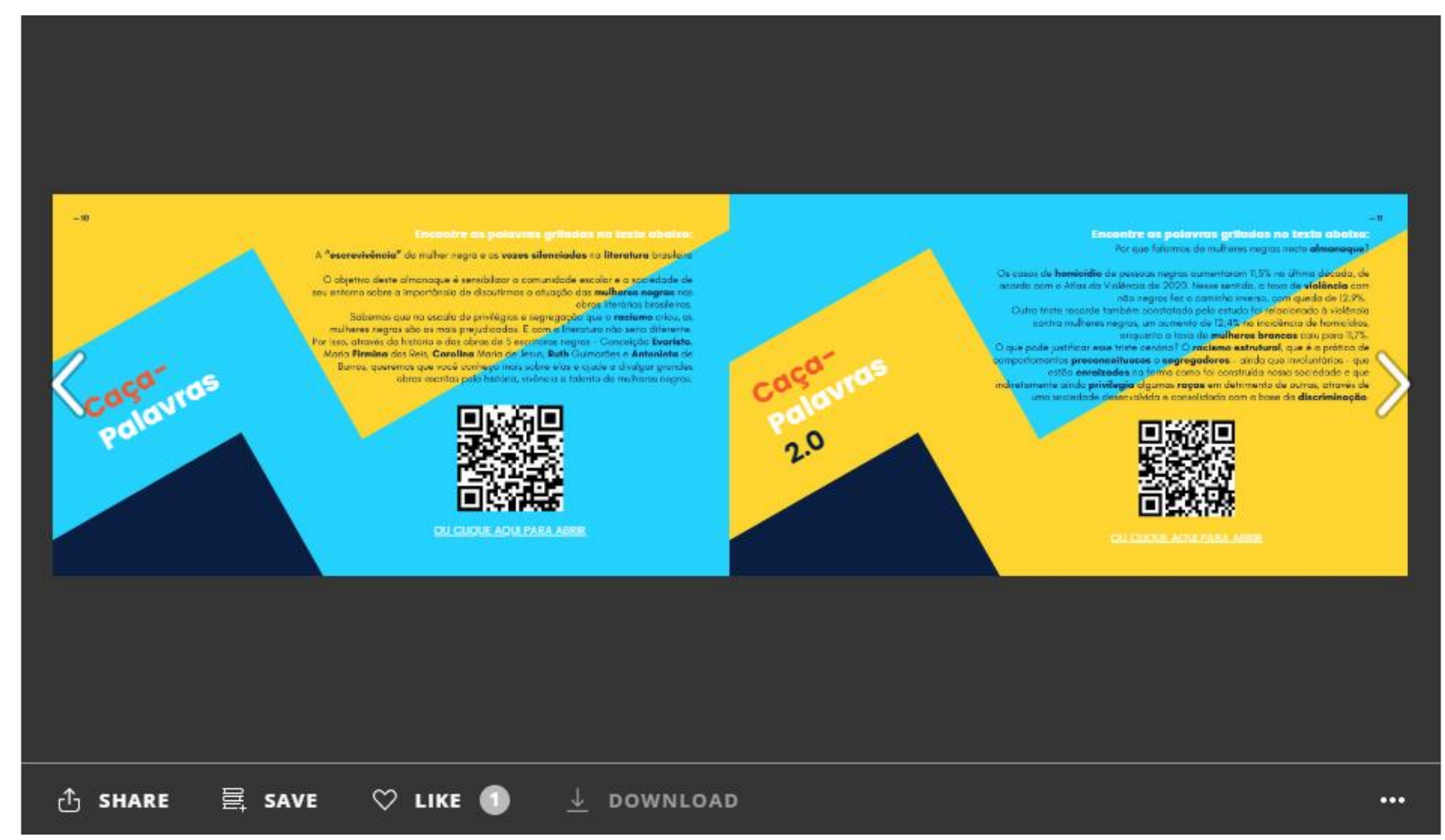

Figura 1: Páginas 10 e 11 do Almanaque Digital, disponível através do link: https://issuu.com/anadairmoraes/docs/almanaque_digital_escreviv_ncia

Após a conclusão do almanaque digital, participamos de uma aula on-line com aproximadamente 30 alunos de Ensino Médio Integral de uma Escola Estadual do interior de São Paulo, matriculados em uma disciplina eletiva ministrada por duas professoras: uma professora de Língua Portuguesa e uma de História.

A aula foi realizada em maio de 2021, durante a pandemia de covid-19, conforme os pressupostos da Didática Histórico-crítica (GASPARIN, 2005). Inicialmente, foram expostos os objetivos da aula e levantados questionamentos para verificar o repertório dos alunos e, ao mesmo tempo, mobilizá-los para a discussão. Após essa Prática Social Inicial e a Problematização, foi apresentado o almanaque digital aos alunos com a leitura de alguns trechos. Enquanto eles desenvolviam as atividades, discutimos alguns conteúdos e buscamos promover reflexões relacionadas às questões de gênero e raça. Por fim, solicitamos que os alunos preenchessem um formulário a fim de avaliarmos a receptividade e as contribuições do almanaque digital para o 
alcance dos objetivos pretendidos. Além desse formulário, após algumas semanas, as professoras responsáveis pela disciplina eletiva também avaliaram os efeitos da ferramenta de aprendizagem e da discussão realizada na oportunidade da apresentação do almanaque digital, dados que também integram os resultados desse projeto.

O almanaque tem como conteúdo a história das seguintes escritoras: Antonieta de Barros, Carolina Maria de Jesus, Conceição Evaristo, Maria Firmina dos Reis e Ruth Guimarães. É claro que se trata de um recorte, dada a extensa produção e a quantidade de autoras na literatura afrobrasileira. A expectativa com essa escolha foi dar conta, minimamente, de uma diversidade de escritoras, ampliando a visibilidade da mulher negra, das suas lutas e suas "escrevivências".

\section{Texto e contexto em algumas escrevivências}

De acordo com Antonio Candido (2006), texto e contexto estão dialeticamente articulados. Assim, “o externo (no caso, o social) importa não como causa, nem como significado, mas como elemento que desempenha um certo papel na constituição da estrutura, tornando-se, portanto, interno" (p.14). Em outras palavras, o social não contextualiza apenas uma época ou uma cultura, mas constitui a produção artística, por isso o externo se torna interno.

Assim, para estudar uma obra, o mestre recomenda que "a primeira tarefa é investigar as influências concretas exercidas pelos fatores socioculturais" que "se ligam à estrutura social, aos valores e ideologias, às técnicas de comunicação" (CANDIDO, 2006, p.31). De forma mais detalhada, o autor explica que "os primeiros se manifestam mais visivelmente na definição da posição social do artista, ou na configuração de grupos receptores; os segundos, na forma e conteúdo da obra; os terceiros, na sua fatura e transmissão" (CANDIDO, 2006, p.31).

Entender, portanto, a literatura afro-brasileira, especialmente aquela produzida por mulheres negras, implica reconhecer a posição social ocupada por essas mulheres, os temas e estilos adotados, a repercussão pretendida e causada no público. Embora seja múltipla, conforme adotado por Conceição Evaristo e reproduzido no título deste trabalho, optamos em focar uma literatura caracterizada como "escrevivência", ou seja, aquela que insere a vivência como parte e motivo da escrita.

Isso significa que, diferente de produções em que a mulher negra é apresentada como personagem estereotipado, procuramos resgatar aqui a mulher negra que ocupa o lugar de sujeito da escrita, que adota e explicita uma visão de mundo, que recupera a história de luta do seu povo, que apresenta a riqueza das tradições culturais e religiosas, que denuncia a violência, a 
marginalização e o preconceito sofridos através de vocabulário, ritmo e entonações, que ressignificam os padrões hegemônicos, sendo porta-vozes de uma comunidade (DUARTE, 2014).

A seguir, apresentamos uma breve descrição dessas escritoras, incluindo referências a textos e contextos, cujos conteúdos embasaram a construção do almanaque digital.

Antonieta de Barros viveu em Florianópolis/SC, no período de 1901 a 1952. Teve uma infância muito difícil, por ser órfã de pai e filha de escrava liberta. Apenas aos 17 anos conseguiu ingressar na Escola Normal Catarinense, curso que foi concluído em 1921 (LITERAFRO, 2018).

No ano seguinte à sua formatura, fundou um curso primário de alfabetização que levava o seu nome: "Curso Particular Antonieta de Barros", destinado a pessoas carentes.

Nos anos 1920, começou a trabalhar como jornalista. Fundou e dirigiu o jornal A Semana e a revista Vida Ilhoa, além de ter suas crônicas e artigos publicados em diversos outros veículos. Em 1937, escreveu o livro Farrapos de Ideias, sob o pseudônimo "Maria da Ilha" (A COR DA CULTURA, 2010).

Antonieta teve bastante destaque no âmbito político, sendo a primeira deputada mulher do estado de Santa Catarina e a primeira deputada estadual negra do Brasil. Foi uma pioneira no combate às desigualdades de gênero e raça. Até 2012, ela era a única pessoa negra a assumir um mandato na Assembleia Legislativa Catarinense (MEMÓRIA POLÍTICA DE SANTA CATARINA, 2020).

Carolina Maria de Jesus nasceu em Sacramento/MG em 1914 e morreu em São Paulo/SP em 1977. De família humilde, viveu com a mãe e sete irmãos. Conseguiu estudar no colégio Allan Kardec, custeado pela patroa de sua mãe. Aos 23 anos, mudou-se para São Paulo em busca de melhores condições de vida (LITERAFRO, 2020).

Teve seu primeiro texto publicado em 1959, após o jornal Folha da Noite enviar o repórter Audálio Dantas para escrever uma matéria sobre a favela do Canindé, onde ela morava. Ele, quando apresentado à Carolina e aos seus diários, percebeu que era aquilo que estava procurando. Em 1960, publicou seu primeiro livro, Quarto de Despejo: Diário de uma Favelada, com edição do mesmo repórter. A obra vendeu cerca de dez mil exemplares na primeira semana e foi traduzida para diversos idiomas, sendo distribuída em mais de quarenta países. A autora ainda publicou Casa de Alvenaria (1961), Pedaços de Fome (1963) e Provérbios (1963), porém nenhum obteve resultado sequer próximo ao do primeiro livro (LITERAFRO, 2020). 
Apenas anos após sua morte, Carolina voltou a ter reconhecimento do público e da imprensa. E, em fevereiro de 2021, recebeu o título de Doutora Honoris Causa, em homenagem póstuma feita pela Universidade Federal do Rio de Janeiro - UFRJ (COUTINHO, 2021).

Conceição Evaristo nasceu em 1946, em uma comunidade pobre de Belo Horizonte/MG. É a segunda filha de uma família de nove irmãos, a primeira de sua casa a ter diploma universitário. Sua mãe e tias eram lavadeiras e domésticas, por isso o primeiro emprego da escritora foi como diarista, que conciliou com os estudos até 1971. Sempre disse que não cresceu rodeada de livros, mas envolta em palavras (LITERAFRO, 2021).

Após concluir o curso normal em Belo Horizonte, mudou-se para o Rio de Janeiro, onde passou em um concurso público na Prefeitura Municipal e graduou-se em Letras pela Universidade Federal do Rio de Janeiro - UFRJ. É mestre em Literatura Brasileira pela Pontifícia Universidade Católica - PUC/RJ e doutora em Literatura Comparada pela Universidade Federal Fluminense UFF (ENCICLOPÉDIA ITAÚ CULTURAL, 2021).

Professora aposentada, estreou como escritora no início dos anos 1990, publicando uma série de textos com o grupo Quilombhoje. Entre suas obras, destacam-se Ponciá Vicêncio (2003), Becos da Memória (2006) e Olhos d'água (2014) (BRANDINO, 2021).

Maria Firmina dos Reis nasceu em São Luís do Maranhão/MA, em 1825, e morreu em Guimarães/MA, em 1917. Ficou órfã aos 5 anos e, por ter ficado com uma tia materna que possuía uma boa condição familiar, teve acesso à educação, à literatura e a boas escolas, o que não era comum para mulheres negras da época (BRANDINO, 2021).

Formou-se em Pedagogia e, aos 25 anos, foi aprovada em um concurso público e nomeada professora de primeiras letras de Guimarães, sendo a primeira professora negra a ocupar essa cadeira. Em 1859, publicou o romance Úrsula, que narra a história de um triângulo amoroso que tem um destino trágico mediante a sociedade patriarcal escravista. A obra deu início ao movimento literário afro-brasileiro e constituiu-se um primeiro passo para a abolição da escravatura no país. Outras obras de destaque são Gupeva (1861), A Escrava (1887) e Hino da Libertação dos Escravos (1888) (ENCICLOPÉDIA ITAÚ CULTURAL, 2021).

Em 1880, recebeu o título de Mestra Régia em História da Educação Brasileira e fundou a primeira escola mista e gratuita do Maranhão, uma das primeiras do Brasil. Aposentou-se em 1881, sempre atuando como professora em Guimarães (BRANDINO, 2021). 
Ruth Guimarães nasceu em 1920 e morreu em 2014, em Cachoeira Paulista/SP. Ainda na infância, apaixonou-se pela literatura e, aos 10 anos, publicou seus primeiros versos em jornais da cidade do vale paraibano (VEIGA, 2020).

Aos 17 anos, mudou-se para São Paulo para estudar e trabalhar. Formou-se em Letras Clássicas pela Universidade de São Paulo (USP). Trabalhou como escritora, tradutora e revisora de textos. A autora tem mais de quarenta livros publicados, seja como autora, tradutora ou revisora. Entre eles, destacam-se Agua Funda (1946), obra que a projetou para o reconhecimento nacional, Os Filhos do Medo (1950) e Dicionário da Mitologia Grega (1972) (D’ONOFRIO, 2020).

Ruth é considerada a primeira escritora brasileira negra a ter projeção nacional e, em 2008, foi eleita para a Academia Paulista de Letras, sendo a primeira escritora negra a conseguir tal feito (D'ONOFRIO, 2020).

\section{Alguns resultados da "experivência"}

Articulando a exigência acadêmica com a demanda escolar, optamos por desenvolver um almanaque digital que proporcionasse ao educando conhecer um pouco da vida e da obra de escritoras negras, a fim de dar visibilidade a essas pessoas e produções, assim como promover reflexões sobre o racismo e o machismo ainda tão presentes em nossa sociedade.

Antes da aula com os alunos, fizemos uma reunião on-line com as professoras responsáveis pela disciplina para apresentar o almanaque digital e discorrer sobre o plano de aula. Ao longo da reunião, as professoras falaram sobre os conteúdos abordados na eletiva e como estava o andamento da disciplina.

Após a apresentação do almanaque digital, as duas professoras elogiaram o trabalho e uma delas referiu ter gostado muito do formato: "é simples, objetivo e cativante". Vale ressaltar que as professoras se inspiraram em nossa proposta para sugerir aos alunos a produção autoral de um almanaque com a denominação "Almanaque das Marias", título da disciplina atribuído após a parceria com as graduandas.

Durante a aula on-line com os alunos, alguns participaram oralmente, outros via chat $\mathrm{e}$ praticamente todos responderam a avaliação final. No chat, houve manifestações de surpresa sobre, por exemplo, as biografias das autoras. A maioria dos alunos não conhecia as escritoras negras brasileiras apresentadas.

Uma aluna registrou o desejo de ser escritora, valorizando a diversidade de autores que devem estar presentes na cena escolar: "Estou escrevendo um livro e acho muito importante entender essa divergência de cada escritora. Então essa reunião me trouxe muito conhecimento e enriquecimento.”. 
A escrita literária trouxe empoderamento para a mulher negra através da narrativa de suas vivências (SOUZA, 2019). Assim, é preciso incentivar a escrevivência também das alunas.

Foi proposta uma atividade de caça-palavras para ampliar a interação e o debate com os alunos. Com palavras como racismo, literatura, mulheres negras, vozes silenciadas, entre outras, identificamos que o jogo digital contribuiu para despertar uma reflexão sobre o tema.

Gráfico 1 - Resposta ao questionário final

O almanaque despertou em você alguma reflexão sobre o racismo ou o machismo presente na literatura ou na sociedade?

19 respostas

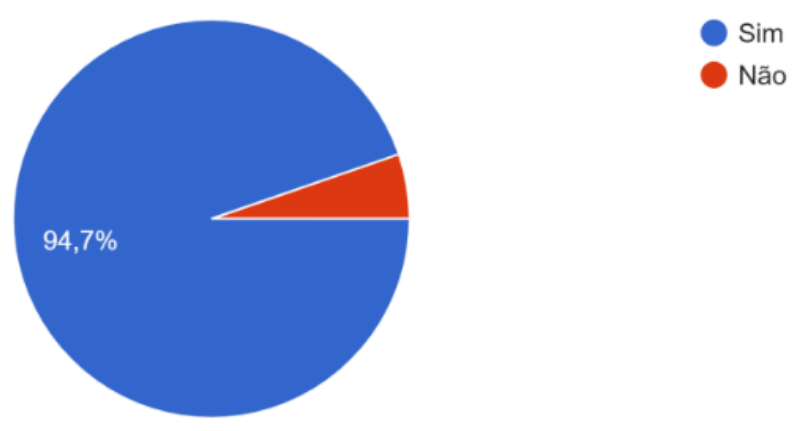

\section{FONTE: XXXXX}

De acordo com os dados de avaliação realizada no final da aula on-line, o almanaque despertou a reflexão de praticamente todos os alunos, atingindo $94,7 \%$ dos respondentes.

Nas respostas dissertativas que detalham esse despertar, percebe-se:

- a descoberta da amplitude do racismo: "Descobri que o racismo vai muito além do que a mídia mostra.";

- a percepção das dificuldades enfrentadas por essas autoras: "Eu não tinha noção de que era tão difícil ser uma escritora negra, o quanto elas tiveram dificuldade nesse caminho por causa dos preconceitos";

- a crítica à naturalização e perpetuação do racismo e machismo: "Infeližmente isso está presente na nossa sociedade há muito tempo e muita gente acha isso comum, mas não é, isso é inaceitável a todos";

- a reivindicação da igualdade entre as raças e gêneros: "Todos nós somos iguais independente de cor e gênero".

Como o machismo e o racismo operam, muitas vezes, de maneira silenciosa, mas percorrendo o tempo nas profundezas da cultura, torna-se dificultoso seu combate. Daí a 
importância dessas atividades didático-pedagógicas e literárias, no sentido de promover o acesso a outras narrativas para refletir e ressignificar nossas concepções e ações.

As vulnerabilidades vivenciadas pela população negra são produtos da história criminosa da escravidão. $\mathrm{Na}$ atualidade, esta vive e sobrevive pagando a conta dos antepassados que não escolheram esse caminho de perversidade, atrocidades e acúmulos de desvantagens. (MADEIRA; GOMES, 2018, p.467).

Enquanto os alunos concluíam um dos jogos do almanaque digital, foi lida uma "pílula literária” de Conceição Evaristo, o texto “Vozes-mulheres” (EVARISTO, 2017). Na oportunidade, explicou-se o conceito "escrevivência” mencionado pela autora, que significa escrever sobre a vida, relatar em uma obra literária as vivências pessoais e de um povo, os lutos e os sofrimentos de um ser singular e, ao mesmo tempo, universal.

Nas palavras da autora,

\begin{abstract}
Escrevivência, em sua concepção inicial, se realiza como um ato de escrita das mulheres negras, como uma ação que pretende borrar, desfazer uma imagem do passado [...] E se ontem nem a voz pertencia às mulheres escravizadas, hoje a letra, a escrita, nos pertencem também [...] Nossa escrevivência traz a experiência, a vivência de nossa condição de pessoa brasileira de origem africana, uma nacionalidade hifenizada, na qual me coloco e me pronuncio para afirmar a minha origem de povos africanos e celebrar a minha ancestralidade e me conectar tanto com os povos africanos, como com a diáspora africana. Uma condição particularizada que me conduz a uma experiência de nacionalidade diferenciada [...] ao mesmo tempo, tenho tido a percepção que, mesmo partindo de uma experiência tão específica, a de uma afro-brasilidade, consigo compor um discurso literário que abarca um sentido de universalidade humana. (EVARISTO, 2020, p.30-31).
\end{abstract}

Essa literatura afro-brasileira, portanto, expressa a "consciência social do negro e se estabelece como um processo contínuo de afirmação identitária", adquirindo fundamentalmente um sentido político (ABRANTES, 2020, p.215).

Uma questão feita pelas graduandas para instigar os alunos à reflexão foi: "será que ainda hoje contribuímos para que o machismo e o racismo continuem enraizados em nossa sociedade?”.

A partir dessa indagação, os alunos deram depoimentos e escreveram no chat suas vivências, especialmente relacionadas ao preconceito e racismo. Um deles referiu já ter sofrido racismo dentro e fora da escola:

"[...] Isso é real, eu já sofri com racismo, dentro da escola, fora dela, é tipo, inconveniente até demais [...] desde mercado até shopping já fui seguido, é surreal isso" 
Outra aluna complementou:

$$
\text { "[... A gente não pode aceitar isso como natural, né?" }
$$

Não podemos! E, por essa razão, esses temas devem ser apresentados e discutidos com os educandos em busca de uma consciência crítica e transformadora na e para a sociedade.

Ao longo da aula, vários alunos escreveram no chat que estavam "amando" a aula, o que demonstra o interesse e a necessidade desse debate.

\section{"Mesmo estando em pleno século XXI, são aqueles pequenos comentários e piadas que incomodam imensamente e precisam ser refletidos e discutidos por não apenas estarem presentes como um problema social, mas também moral, porque muitas vezes são taxados de 'picuinhas'."}

Percebe-se a riqueza dos relatos, tanto no sentido de os alunos tomarem conhecimento da história, da obra e dos enfrentamentos dessas escritoras negras, como de avaliarem o preconceito e o machismo, ainda presentes, como inaceitáveis.

Além da avaliação realizada no final da aula pelas graduandas, as professoras responsáveis pela eletiva também aplicaram, em uma aula futura, um questionário avaliativo sobre a aula e a ferramenta tecnológica. Ao serem questionados se tinham gostado do almanaque digital, 91,7\% dos alunos afirmaram que sim e $8,3 \%$ afirmaram que parcialmente.

Gráfico 2 - Resposta ao questionário aplicado em aula futura pelas professoras Vocês gostaram do Almanaque desenvolvido pelas parceiras da UNIVESP? 24 respostas

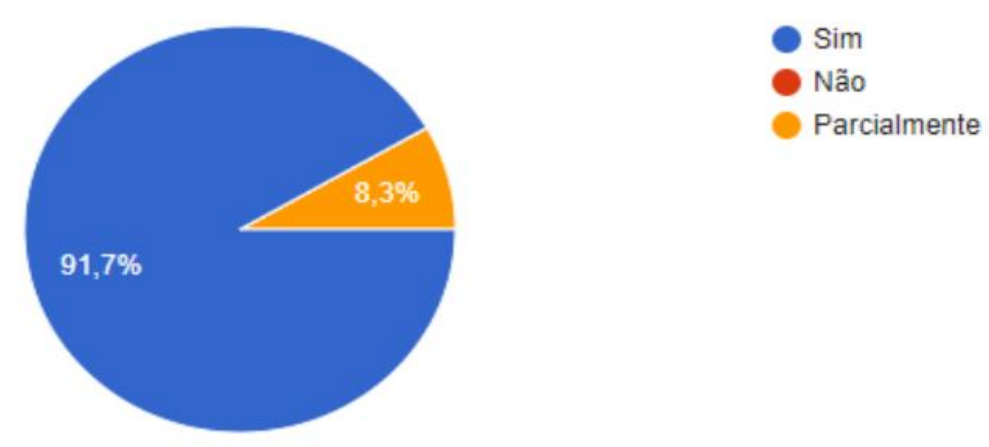

FONTE: XXXX 
Um outro dado importante levantado pelas professoras foi que o almanaque digital despertou o interesse dos alunos pela literatura. Conforme é possível visualizar no gráfico 3, 41,7\% dos alunos afirmaram que não gostavam e agora estão mais interessados em literatura e 37,5\% afirmaram que já se interessavam, mas que o encontro os motivou ainda mais.

Gráfico 3 - Resposta ao questionário aplicado em aula futura pelas professoras
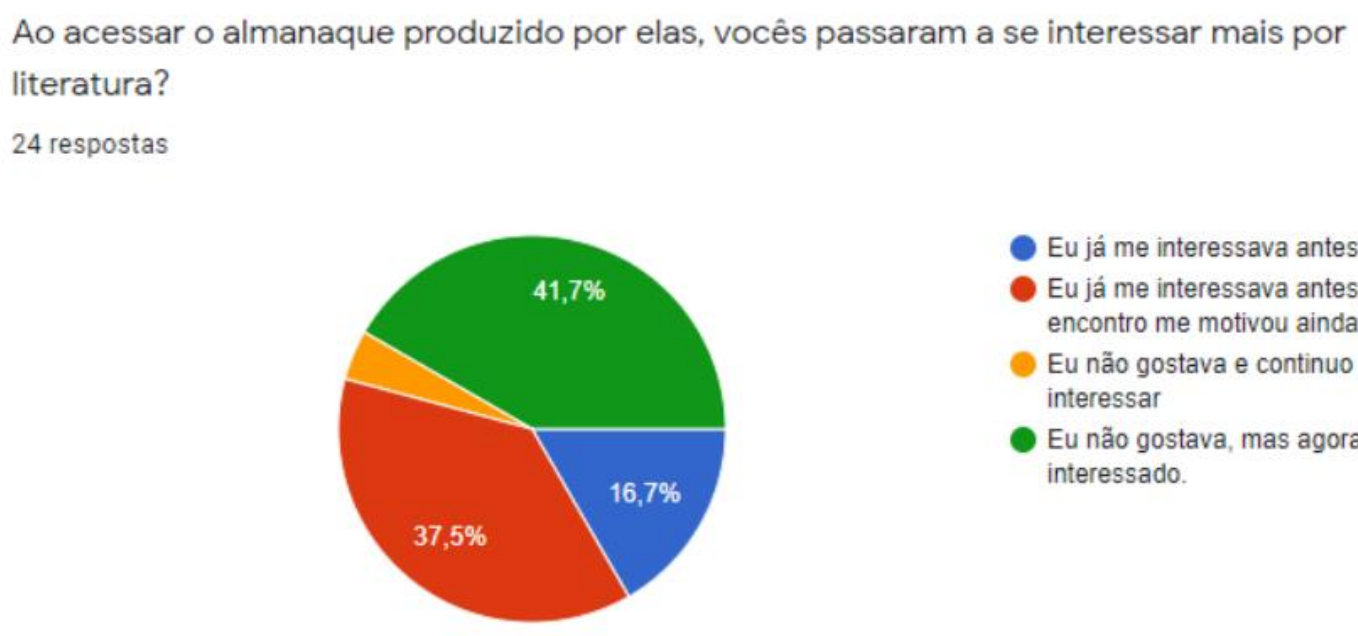

Eu já me interessava antes

Eu já me interessava antes, mas o encontro me motivou ainda mais

Eu não gostava e continuo sem me interessar

Eu não gostava, mas agora estou mais interessado.

FONTE: XXX

\section{Considerações finais (ou iniciais?)}

Com objetivo de promover uma reflexão sobre o machismo e o racismo estrutural a partir de uma tecnologia pedagógica, elaboramos um almanaque digital com conteúdos sobre a vida e a obra de escritoras negras, a fim de sensibilizar a comunidade escolar sobre os retrocessos que a sociedade patriarcal e racista representa para a igualdade entre as pessoas.

Entende-se que integrar as tecnologias digitais ao processo ensino-aprendizagem pode promover a transmissão dos conhecimentos e da cultura historicamente acumulada, tornando o aprendizado mais interessante, dinâmico, instigante e participativo (SEB, 2019), estimulando o compreender, o sentir e o transformar (MACHADO; LIMA, 2017).

Realizou-se uma aula on-line com alunos do Ensino Médio vinculados a uma disciplina eletiva de uma Escola Estadual Integral do Estado de São Paulo para apresentação de um almanaque digital com conteúdos sobre a luta de mulheres negras por espaço, justiça e igualdade na vida e na literatura e, a partir disso, promover uma reflexão sobre gênero e raça.

Apesar de ter sido uma experiência pontual, os resultados alcançados tanto em relação à discussão dos temas como em relação à estratégia de ensino adotada foram considerados positivos 
pelos alunos, com apresentação de relatos, reflexões e testemunhos. Além de conhecerem escritoras que, até então, eram desconhecidas por eles, puderam refletir sobre o processo de exclusão e invisibilidade sofrido por elas, assim como compartilharam histórias pessoais e questionaram a naturalização especialmente do racismo, dificultando o acesso aos direitos de uma população.

É claro que uma aula não é suficiente para discutir todo o conteúdo necessário relacionado a esse tema. Entretanto, a expectativa é que esse almanaque digital seja um material didáticopedagógico disponibilizado pela escola, a fim de instigar outros alunos e familiares a refletirem sobre a condição vivenciada pela mulher negra e sua determinação em usar a escrita na luta por igualdade e justiça.

E, assim, que possamos inspirar e lutar para que a mulher negra tenha seu espaço na literatura brasileira e a sociedade democrática alcance, de fato, igualdade racial e de gênero.

\section{Referências}

A COR da Cultura. Antonieta de Barros, 2010. Disponível em: http://antigo.acordacultura.org.br/herois/heroi/antonietadebarros. Acesso em: 30 abr. 2021.

ABRANTES, E. L. Raça e cor nos textos em prosa. In: VILHAGRA, L. T. F. R. et al. Estudos de literatura: análise da narrativa em suas diversas manifestações. Porto Alegre: SAGAH, 2020. p. 213-228.

ALVES, L. A. S.; SANTOS, B. R.; FREITAS, L. G. Impacto das ações formativas no uso de tecnologias nas práticas docentes. Psicologia: Teoria e Prática, São Paulo, v. 19, n. 3, p. 316-334, 2017. Disponível em: http://pepsic.bvsalud.org/pdf/ptp/v19n3/v19n3a14.pdf. Acesso em: 03 maio 2021.

ALMEIDA, S. Racismo Estrutural. São Paulo: Jandaíra, 2018.

BERNARDES, M. E. M. Ensino e aprendizagem como unidade dialética na atividade pedagógica. Revista Semestral da Associação Brasileira de Psicologia Escolar e Educacional (ABRAPEE), v. 13, n. 2, p. 235-242, 2009. Disponível em: https://www.scielo.br/pdf/pee/v13n2/v13n2a05.pdf. Acesso em: 04 maio 2021.

BRANDINO, L. Conceição Evaristo. Brasil Escola, 2021. Disponível em: https://brasilescola.uol.com.br/literatura/conceicao-evaristo.htm. Acesso em: 14 abr. 2021.

BRANDINO, L. Maria Firmina dos Reis. Português, 2021. Disponível em: https://www.portugues.com.br/literatura/maria-firmina-dos-reis.html. Acesso em: 18 abr. 2021.

BRASIL, Lei n ${ }^{\circ}$ 10.639, de 9 de janeiro de 2003. Altera a Lei no 9.394, de 20 de dezembro de 1996, que estabelece as diretrizes e bases da educação nacional, para incluir no currículo oficial da 
Rede de Ensino a obrigatoriedade da temática "História e Cultura Afro-Brasileira", e dá outras providências. Brasília, DF: Palácio do Planalto, 2003. Disponível em: https://www.planalto.gov.br/ccivil_03/Leis/2003/L10.639.htm. Acesso em: 28 jun. 2021.

BRASIL, Lei no 11.645, 10 de março de 2008. Altera a Lei no 9.394, de 20 de dezembro de 1996, modificada pela Lei $\mathrm{n}^{\circ} 10.639$, de 9 de janeiro de 2003, que estabelece as diretrizes e bases da educação nacional, para incluir no currículo oficial da rede de ensino a obrigatoriedade da temática "História e Cultura Afro-Brasileira e Indígena". Brasília, DF: Palácio do Planalto, 2008. Disponível em: http://www.planalto.gov.br/ccivil_03/_Ato2007-2010/2008/Lei/L11645.htm. Acesso em: 28 jun. 2021.

CANDIDO, A. Literatura e sociedade. 9. ed. Rio de Janeiro: Ouro sobre Azul, 2006.

CARNEIRO, S. Enegrecer o Feminismo: A situação da mulher negra na América Latina a partir de uma perspectiva de gênero. In: ASHSOKA, T. Racismos Contemporâneos. (org.). Rio de Janeiro: Cidadania, 2003.

COUTINHO, S. Consuni aprova título de Doutora Honoris Causa a Carolina Maria de Jesus. Centro de Filosofia e Ciências Humanas - UFRJ, fev./2021. Disponível em:

http:/ / www.cfch.ufrj.br/index.php/27-noticias/1415-consuni-aprova-titulo-de-doutora-honoriscausa-a-carolina-maria-de-jesus. Acesso em: 30 abr. 2021.

D’ONOFRIO, S. Ruth Guimarães: uma romancista negra na imprensa brasileira dos anos 1940. Acervo, Rio de Janeiro, v. 33, n. 1, p. 189-203, 2020. Disponível em:

http://revista.arquivonacional.gov.br/index.php/revistaacervo/article/view/1524/1438. Acesso em: 23 mar. 2021.

DUARTE, E. A. Por um conceito de literatura afro-brasileira. In: DUARTE, E. A. (coord.). Literatura afro-brasileira: 100 autores do século XVIII ao XXI. 2. ed. Rio de Janeiro: Pallas, 2014. p.17-45.

DUARTE, N. As pedagogias do aprender a aprender e algumas ilusões da assim chamada sociedade do conhecimento. Revista Brasileira de Educação, n. 18, p. 35-40, 2001. Disponível em: https://www.scielo.br/pdf/rbedu/n18/n18a04.pdf. Acesso em: 04 maio 2021.

ENCICLOPÉDIA Itaú Cultural de Arte e Cultura Brasileiras. Conceição Evaristo. São Paulo: Itaú Cultural, 2021. Disponível em: http://enciclopedia.itaucultural.org.br/pessoa6851/conceicaoevaristo. Acesso em: 13 abr. 2021.

ENCICLOPÉDIA Itaú Cultural de Arte e Cultura Brasileiras. Maria Firmina dos Reis. São Paulo: Itaú Cultural, 2021. Disponível em: http:/ / enciclopedia.itaucultural.org.br/pessoa641361/mariafirmina-dos-reis. Acesso em: 18 abr. 2021.

EVARISTO, C. Da representação à auto-apresentação da Mulher Negra na Literatura Brasileira. Revista Palmares, 2005. Disponível em: http://www.palmares.gov.br/sites/000/2/download/52\%20a\%2057.pdf. Acesso em: 24 abr. 2021.

EVARISTO, C. Literatura negra: uma poética de nossa afro-brasilidade. Scripta, Belo Horizonte, v. 13, n. 25, p. 17-31, 2009. 
EVARISTO, C. Escrevivência - Episódio 01 da série Ecos da Palavra, 2017. 1 vídeo. [Entrevista cedida a] Renata Codagan. Publicado pelo canal Instituto de Arte Tear. Disponível em: https://www.youtube.com/watch?v=4EwKXpTIBhE\&t=16s. Acesso em: 8 maio 2021.

EVARISTO, C. Vozes-mulheres. In: Vários autores. 50 poemas de revolta. São Paulo: Companhia das Letras, 2017.

EVARISTO, C. A escrevivência e seus subtextos. In: DUARTE, C. L.; NUNES, I. R. Escrevivência: a escrita de nós. Reflexões sobre a obra de Conceição Evaristo. Rio de Janeiro: Mina Comunicação e arte, 2020. p.26-46.

GASPARIN, J. L. Uma didática para a pedagogia histórico-crítica. 3. ed. Campinas: Autores Associados, 2005.

IPEA. Atlas da violência, 2020. Disponível em https://www.ipea.gov.br/atlasviolencia/arquivos/downloads/8132-atlas-da-violencia-2020infografico.pdf. Acesso em: 21 abr. 2021.

LITERAFRO. Antonieta de Barros. Literafro, 2018. Disponível em: http://www.letras.ufmg.br/literafro/autoras/57-antonieta-de-barros. Acesso em: 30 abr. 2021.

LITERAFRO. Carolina Maria de Jesus. Literafro, 2020. Disponível em: http://www.letras.ufmg.br/literafro/autoras/58-carolina-maria-de-jesus. Acesso em: 30 abr. 2021.

LITERAFRO. Conceição Evaristo. Literafro, 2021. Disponível em: http://www.letras.ufmg.br/literafro/autoras/188-conceicao-evaristo. Acesso em: 14 abr. 2021.

MACHADO, F. C.; LIMA, M. F. W. P. O Uso da Tecnologia Educacional: um fazer pedagógico no cotidiano escolar. SCIENTIA CUM INDUSTRIA, v. 5, n. 2, p. 44-50, 2017. Disponível em: http://www.ucs.br/etc/revistas/index.php/scientiacumindustria/article/view/5280/pdf. Acesso em: 03 maio 2021.

MADEIRA, Z.; GOMES, O. D. D. Persistentes desigualdades raciais e resistências negras no Brasil contemporâneo. Serv. Soc. Soc., São Paulo, v. 133, p. 463-479, 2018. Disponível em: https://www.scielo.br/pdf/sssoc/n133/0101-6628-sssoc-133-0463.pdf. Acesso em: 30 abr. 2021.

MEMÓRIA POLÍTICA DE SANTA CATARINA. Biografia Antonieta de Barros. 2020. Disponível em: http://memoriapolitica.alesc.sc.gov.br/biografia/68-Antonieta_de_Barros. Acesso em: 01 maio 2021.

NASCIMENTO, K. A.; BENATTI, A. R. "Maria": A representação da mulher negra e do racismo no conto de Conceição Evaristo. Revista de Estudos de Literatura, Cultura e Alteridade, Igarapé, v. 13, n. 1, p. 38-65, 2020. Disponível em:

https://www.periodicos.unir.br/index.php/igarape/article/view/5161. Acesso em: 24 abr. 2021.

REDE BRASIL ATUAL. Índice de feminicídio aumenta em 2020, e mulheres negras são as principais vítimas. 17 set. 2020. Disponível em: 
https://www.redebrasilatual.com.br/cidadania/2020/09/feminicidio-2020-mulheres-negras/ Acesso em: 21 abr. 2021.

SAMARA, E. M. O que mudou na família brasileira?: da colônia à atualidade. Psicologia USP, v. 13, n. 2, p. 27-48, 2002. Disponível em:

https://www.revistas.usp.br/psicousp/article/view/53500. Acesso em: 9 maio 2021.

SISTEMA EDUCACIONAL BRASILEIRO (SEB). Entenda a importância da tecnologia na educaşão atual, 26 fev. 2019. Disponível em: https:// catracalivre.com.br/educacao/entenda-a-importanciada-tecnologia-na-educacao-atual/. Acesso em: 03 maio 2021.

SOUZA, F. Gênero e "raça" na literatura brasileira. Estudos de Literatura Brasileira Contemporânea, n. 32, p. 103-112, 2008, Disponível em: https://www.redalyc.org/pdf/3231/323127096008.pdf. Acesso em: 24 abr. 2021.

SOUZA, F. Mulheres negras escritoras. Revista Crioula, n. 20, p. 20-22, 2017. Disponível em: https://www.revistas.usp.br/crioula/article/view/141317/136840. Acesso em: 01 maio 2021.

SOUZA, F. S. Literatura afro-feminina brasileira: uma forma de combate ao silenciamento e ao racismo. Di nuove e vecchie schiavitù, 2019. Disponível em:

https://riviste.unimi.it/index.php/AMonline/article/view/11328/10711. Acesso em: 01 maio 2021.

VEIGA, E. Ruth Guimarães: o centenário da escritora pioneira que colocou a identidade negra no centro de sua obra. $B B C$, nov./2020. Disponível em:

https://www.bbc.com/portuguese/brasil-55024124. Acesso em: 25 mar. 2021.

WERNECK, J.; IRACI, N.; CRUZ, S. Introdução. In: WERNECK, J. (org.). Mulheres negras na primeira pessoa. Porto Alegre: Redes Editora, 2012. Disponível em:

https://www.geledes.org.br/wp-

content/uploads/2014/05/Mulheres_Negras_na_Primeira_Pessoa.pdf. Acesso em: 24 abr. 2021. 